\title{
PENGARUH PEMBELAJARAN BERBASIS MASALAH TERHADAP MINAT BELAJAR KIMIA PESERTA DIDIK
}

\author{
Wisnu Prammana Surya dan Indyah Sulistyo Arty \\ Pascasarjana Universitas Negeri Yogyakarta \\ email: wisnuprammana.2018@student.uny.ac.id
}

\begin{abstract}
Abstrak
Penelitian ini bertujuan untuk mengetahui pengaruh penerapan model pembelajaran problem-based learning (PBL) terhadap minat belajar kimia peserta didik pada topik kesetimbangan kimia. Penelitian ini merupakan penelitian kuantitatif jenis quasi eksperiment dengan menggunakan posttest only design. Penelitian dilaksanakan di SMA Negeri 6 Pekanbaru. Sampel ditentukan menggunakan teknik simple random sampling. Data minat belajar kimia peserta didik dikumpulkan menggunakan kuesioner berdasarkan lima kategori, yaitu tingkat minat peserta didik terhadap kimia, pilihan pribadi, peran guru, minat situasional, dan kemauan mengikuti pembelajaran kimia. Data kuantitatif dianalisis menggunakan mean, standar deviasi, persentase, dan uji hipotesis One-Way ANOVA. Analisis deskriptif digunakan untuk mendeskripsikan minat belajar kimia. Hasil penelitian menunjukkan bahwa terdapat perbedaan signifikan minat belajar kimia antara peserta didik yang menerapkan model pembelajaran PBL dan model pembelajaran ekspositori pada topik kesetimbangan kimia. Minat belajar kimia peserta didik masih tergolong rendah, namun peserta didik yang menggunakan model PBL menunjukkan skor yang lebih tinggi daripada kelas ekspositori. Peserta didik laki-laki lebih tertarik pada kimia daripada peserta didik perempuan.
\end{abstract}

Kata kunci: problem based learning, minat, belajar kimia, kesetimbangan kimia

\section{THE EFFECT OF PROBLEM BASED LEARNING ON STUDENTS' INTEREST IN CHEMISTRY}

\begin{abstract}
This study aims to determine the effect of applying the problem based learning (PBL) learning model to students' interest in learning chemistry on the topic of chemical equilibrium. This research is a quantitative research type of quasi experiment using posttest only design. The study was conducted at SMA Negeri 6 Pekanbaru. The sample was determined using simple random sampling technique. Data on students 'interest in learning chemistry are collected using a questionnaire based on five categories, namely the level of students' interest in chemistry, personal choice, teacher's role, situational interest, and willingness to attend chemistry learning. Quantitative data were analyzed using mean, standard deviation, percentage, and One-Way ANOVA hypothesis testing. Descriptive analysis is used to describe the interest in learning chemistry. The results showed that there were significant differences in interest in learning chemistry between students applying PBL learning models and expository learning models on the topic of chemical equilibrium. Interest in learning chemistry of students is still relatively low, but students who use the PBL model show higher scores than expository classes. Male students are more interested in chemistry than female students.
\end{abstract} Keywords: problem based learning, interest, chemical learning, chemical equilibrium 


\section{PENDAHULUAN}

Perubahan mendasar sedang terjadi pada pembelajaran sains tentang persepsi pendidikan dan hubungan teknologi dengan masyarakat. Perubahan itu terjadi pada kegiatan pendidikan menggunakan pendekatan konstruktivisme (Taber, 2011, p. 40). Kegiatan pendidikan menggunakan berbagai model pembelajaran aktif digunakan dalam proses pembelajaran untuk menghasilkan individu yang kreatif, dapat menyesuaikan diri dengan kerja sama tim, dan mampu menemukan solusi untuk masalah kehidupan seharihari menggunakan pengetahuan dan keterampilan yang diperoleh (Gunter \& Alpat, 2016). Model pembelajaran aktif yang menyediakan interaksi antara peserta didik, antara peserta didik dengan teknologi, dan antara peserta didik dengan guru menggunakan sumber informasi dan teknologi, telah menjadi fokus penelitian pendidikan.

Salah satu upaya pemerintah untuk mengembangkan kegiatan pendidikan tersebut adalah dengan menerapkan Kurikulum 2013. Kurikulum 2013 diharapkan dapat menghasilkan pelajar yang produktif, kreatif, dan inovatif melalui penguatan sikap, keterampilan, serta pengetahuan yang terintegrasi. Hal ini dalam rangka menyongsong perkembangan kehidupan dan ilmu pengetahuan Abad 21. Implementasi Kurikulum 2013 dalam pembelajaran merupakan proses pembelajaran yang dirancang sedemikian rupa agar peserta didik secara mandiri dan aktif mengkonstruk konsep, hukum, atau prinsip melalui tahapan-tahapan mengamati, merumuskan masalah, merumuskan hipotesis, mengumpulkan data dengan berbagai teknik, menganalisis data, menarik kesimpulan, dan mengomunikasikannya (Hosnan, 2014, p. 34). Akan tetapi, tenaga pendidik masih menganut cara konvensional yakni pembelajaran berorientasi teacher centered dan ini kurang sesuai dengan tuntutan kurikulum (Maharani, Rahayu, \& Fajaroh, 2019). Pembelajaran yang berpusat pada peserta didik menjadi studi penelitian yang penting di kalangan pendidik. Peserta didik yang terlibat aktif menghasilkan pengetahuan berasal dari diri mereka sendiri. Kondisi saat ini, peningkatan potensi peserta didik belum difasilitasi dengan baik (Suyanta, Laksono, Fadhilah, \& Rizky, 2019).

Keberhasilan penerapan Kurikulum 2013 dipengaruhi oleh pihak sekolah dalam menerapkan dan memaksimalkan pelaksanaan Standar Proses. Peraturan Menteri Pendidikan dan Kebudayaan Republik Indonesia Nomor 65 Tahun 2013 tentang Standar Proses Pendidikan Dasar dan Menengah menganjurkan untuk mendorong kemampuan peserta didik dalam menghasilkan karya kontekstual, baik individual maupun kelompok dengan menggunakan model pembelajaran yang menghasilkan karya berbasis pemecahan masalah (project-based learning). Model pembelajaran yang diharapkan dalam penerapan Kurikulum 2013 meliputi karakteristik tematik terpadu, pendekatan scientific, discovery learning, problem based learning, dan project based learning. Pembelajaran berbasis masalah atau problem based learning (PBL) adalah salah satu dari model pembelajaran aktif ini (Tarhan, Ayar-Kayali, Urek, \& Acar, 2008).

Pembelajaran menggunakan PBL menuntut guru agar dapat menciptakan masalah berdasarkan hasil kurikulum yang diinginkan, karakteristik peserta didik, dan situasi dunia nyata (Golightly \& Raath, 2015). Komariah, Sofyan, dan Wagiran (2019) menyatakan bahwa kelebihan model ini adalah dapat meningkatkan aktivitas peserta didik, membantu mentransfer pengetahuan mereka dalam memahami 
kehidupan nyata, dan mengembangkan kemampuan berpikir kritis peserta didik. PBL merupakan model pembelajaran yang efektif dalam meningkatkan prestasi akademik peserta didik (Gunter \& Alpat, 2016). PBL berbeda dari pembelajaran yang bersifat konvensional karena peserta didik bekerja dalam tim di seluruh proses pembelajaran dan berusaha mencari solusi untuk skenario masalah dengan mengumpulkan berbagi informasi dan ide. Overton dan Randles (2015) menyatakan bahwa PBL paling mudah diterapkan dalam pembelajaran kimia dalam konteks kehidupan nyata mudah diidentifikasi.

Salah satu topik kimia yang erat kaitannya dengan kehidupan nyata adalah kesetimbangan kimia. Konsep-konsep tentang kesetimbangan kimia yang harus dipahami oleh peserta didik yaitu mencakup kesetimbangan dinamis, tetapan kesetimbangan, dan faktor-faktor yang mempengaruhi pergeseran kesetimbangan. Topik kesetimbangan kimia merupakan salah satu topik yang telah dimasukkan di antara topik-topik dari sebagian besar topik kimia yang sulit untuk dipahami (Akram, Surif, \& Ali, 2014). Konsep kesetimbangan kimia sulit untuk dipahami bahkan oleh peserta didik sekolah menengah.

Model PBL memiliki peran dalam meningkatkan perhatian, aktivitas belajar, dan minat peserta didik terhadap materi yang dipelajarinya. Krapp dan Prenzel (2011) menyatakan bahwa faktor kunci dalam bidang pendidikan sains adalah minat. Seorang pendidik harus mampu meningkatkan minat peserta didik, hal ini dapat dilakukan dengan menghilangkan faktor-faktor yang berperan dalam penurunan minat peserta didik terhadap mata pelajaran kimia (Akram, Ijaz, \& Ikram 2017). Minat sering digambarkan sebagai hubungan individu dengan objek dan memungkinkan seseorang untuk secara sukarela terlibat dalam kegiatan tertentu dan menunjukkan partisipasi serta kepuasan yang disengaja daripada kemalasan terhadap objek tersebut (Çiçek \& Ilhan, 2017). Adodo dan Gbore (2012) mengungkapkan bahwa minat itu lebih diutamakan daripada kedisiplinan dan minat merupakan kunci keberhasilan pendidikan. Jika peserta didik tidak tertarik pada kimia, mereka cenderung tidak berusaha untuk belajar dan memahami makna konsep yang diajarkan kepada mereka. Hal ini menunjukkan bahwa faktor paling efektif yang berkontribusi terhadap keputusan peserta didik untuk belajar kimia adalah minat mereka terhadap kimia (Hofstein \& Mamlok-Naaman, 2011). Berdasarkan uraian di atas, penelitian ini bertujuan untuk mengetahui pengaruh penerapan model pembelajaran PBL terhadap minat belajar kimia peserta didik pada topik kesetimbangan kimia di SMA Negeri 6 Pekanbaru. Kurikulum 2013 telah diterapkan di sekolah tersebut, namun model pembelajaran PBL belum diterapkan dalam proses pembelajaran.

\section{METODE}

Penelitian ini merupakan penelitian kuantitatif dengan jenis penelitian quasi experiment. Penelitian dilaksanakan di SMA Negeri 6 Pekanbaru. Penelitian dilakukakan pada bulan Oktober-November 2019. Desain penelitian yang digunakan adalah posttest only design. Sampel penelitian diambil dengan menggunakan teknik simple random sampling, sehingga terpilih dua kelompok peserta didik yaitu kelompok eksperimen dan kelompok kontrol yang jumlah keseluruhannya 59 orang. Kelompok eksperimen menerapkan model PBL sedangkan kelompok kontrol menerapkan model pembelajaran ekspositori. Skema rancangan penelitian ditunjukkan pada Tabel 1. 
Tabel 1

Rancangan Penelitian Posttest only Design

\begin{tabular}{lcc}
\hline \multicolumn{1}{c}{ Kelompok } & Perlakuan & Posttest \\
\hline Eksperimen & $\mathrm{X}_{1}$ & $\mathrm{Q}$ \\
Kontrol & $\mathrm{X}_{2}$ & $\mathrm{Q}$ \\
\hline
\end{tabular}

Keterangan:

$\mathrm{X}_{1}=$ pembelajaran dengan model (PBL)

$\mathrm{X}_{2}=$ pembelajaran dengan model ekspositori

$\mathrm{Q}=$ kuesioner minat belajar kimia

Instrumen penelitian ini adalah instrumen pembelajaran berupa silabus, Rencana Pelaksanaan Pembelajaran (RPP) dan Lembar Kegiatan Peserta Didik (LKPD) yang digunakan pada proses pembelajaran dan instrumen pengukuran berupa kuesioner yang diberikan kepada peserta didik pada akhir proses pembelajaran. Kuesioner dianalisis agar diperoleh skor masingmasing peserta didik.

Kuesioner digunakan untuk mengumpulkan tanggapan tertutup dari para peserta didik. Kuesioner terdiri dari 30 pernyataan yang 20 diantaranya merupakan pernyataan positif dan 10 pernyataan negatif. Kuesioner yang digunakan berdasarkan lima kategori, yaitu tingkat minat peserta didik terhadap kimia, pilihan pribadi, peran guru (Akram et al., 2017), minat situasional (Basso et al., 2018), dan kemauan mengikuti pembelajaran kimia. Para peserta didik diharapkan untuk menanggapi dengan menyatakan tingkat persetujuan mereka terhadap pernyataan yang diberikan.

Data kuesioner diolah agar diperoleh skor dan nilai minat dari masing-masing peserta didik dan dianalisis menggunakan mean, standar deviasi, persentase, dan menguji hipotesis menggunakan uji statistik parametrik One-Way ANOVA dengan bantuan program IBM SPSS 21.0 for Windows. Adapun analisis deskriptif digunakan untuk mendeskripsikan minat belajar kimia peserta didik.

\section{HASIL PENELITIAN DAN PEMBAHASAN}

Perbedaan minat belajar kimia peserta didik dapat dilihat berdasarkan hasil kuesioner. Nilai rata-rata minat belajar kimia peserta didik kelas eksperimen dan kelas kontrol berturut-turut adalah 72,39 dan 65,22. Hasil analisis uji hipotesis terhadap minat belajar kimia peserta didik menunjukkan signifikansi sebesar 0,001 $(\operatorname{sig}<0,05)$ sehingga dapat disimpulkan bahwa terdapat perbedaan signifikan minat belajar kimia antara peserta didik yang menerapkan model pembelajaran PBL dan model pembelajaran ekspositori pada materi kesetimbangan kimia.

Penerapan model PBL terbukti dapat meningkatan minat peserta didik terhadap pelajaran melalui proses pancingan masalah sehingga peserta didik tergugah untuk memecahkan masalah tersebut melalui penugasan-penugasan yang diberikan oleh guru (Komariah dkk., 2019). Masalah yang diberikan memiliki hubungan erat dalam kehidupan sehari-hari sehingga rasa ingin tahu peserta didik meningkat dan mereka dapat merasakan bahwa topik yang dibahas bermanfaat untuk dipelajari.

Peserta didik dituntut agar dapat berperan aktif dalam proses pemecahan masalah dan berbagi informasi dalam kegiatan kelompok kooperatif. Gunter dan Alpat (2016) menyatakan bahwa model pembelajaran PBL dapat meningkatkan minat peserta didik pada subjek, bahwa mereka merasa seperti peneliti dan ilmuwan sehingga pembelajaran menjadi lebih menyenangkan dan menarik. Pembelajaran dirancang agar peserta didik dapat belajar secara mandiri dalam membangun konsep kesetimbangan kimia melalui tahapantahapan implementasi model PBL yang dapat dilihat sebagai berikut.

Proses pembelajaran menggunakan model PBL diawali dengan penyajian suatu masalah (wacana atau bahan bacaan) 
yang dapat membimbing peserta didik untuk menemukan konsep sesuai dengan tujuan pembelajaran. Guru mendorong dan membimbing peserta didik untuk mengajukan pertanyaan dan mencari informasi. Peserta didik diarahkan untuk dapat mengidentifikasi masalah dari wacana yang diberikan dan menentukan informasi yang mereka perlukan untuk menyelesaikan masalah terkait.

Setelah peserta didik berorientasi pada situasi masalah, guru mengatur peserta didik ke dalam pembelajaran kooperatif dengan membentuk tim kecil sebanyak enam kelompok untuk mengembangkan keterampilan kolaborasi di antara mereka dan membantu kegiatan penyelidikan terhadap masalah secara bersama. Guru membantu peserta didik untuk membuat subtopik pada situasi masalah. Sebagai contoh pada topik konsep kesetimbangan dinamis, dapat dibagi menjadi subtopik arah kesetimbangan, syarat-syarat terjadinya kesetimbangan, dan jenis-jenis kesetimbangan. Peserta didik mengumpulkan informasi dari berbagai sumber untuk menjawab pertanyan yang telah diidentifikasi. Guru terus mengajukan pertanyaan yang membuat peserta didik berpikir tentang materi yang dipelajari. Peserta didik dalam kelompoknya berdiskusi tentang konsep atau materi yang ditemukan, mengolah informasi, dan mengerjakan beberapa soal.

Guru meminta beberapa kelompok untuk mempresentasikan hasil diskusi dan membantu peserta didik yang mengalami kesulitan. Peserta didik mengemukakan pendapat atas presentasi yang dilakukan dan ditanggapi oleh kelompok lain. Salah satu langkah yang perlu dilakukan oleh seorang guru untuk menilai proses diskusi peserta didik yaitu satu anggota kelompok membuat presentasi di akhir penyelidikan masalah (Golightly \& Raath, 2015).
Kemudian, guru membantu peserta didik untuk menganalisis dan mengevaluasi proses berpikir mereka serta keterampilan investigasi dan intelektual yang mereka gunakan. Menyimpulkan tentang poinpoin penting yang muncul dalam kegiatan pembelajaran yang baru dilakukan.

Hasil analisis data menunjukkan bahwa rata-rata skor total minat belajar kimia peserta didik kelas eksperimen dan kelas kontrol berturut-turut adalah 86,8 dan 78,2 dari skor maksimal ideal 120. Kelas eksperimen menunjukkan nilai yang lebih tinggi daripada kelas kontrol. Pada kelas eksperimen, sebanyak 36,7\% (11 peserta didik) mempunyai minat belajar kimia yang tinggi; 63,3\% (18 peserta didik) mempunyai minat belajar kimia yang sedang; dan tidak ada peserta didik yang berada pada minat yang rendah. Kelas kontrol sebanyak 23,3\% (7 peserta didik) mempunyai minat belajar kimia yang tinggi; 73,3\% (22 peserta didik) mempunyai minat belajar kimia yang sedang; dan 3,3\% (1 peserta didik) mempunyai minat belajar kimia yang rendah seperti ditunjukkan pada Gambar 1.

Tingkat persetujuan tertinggi pada faktor tingkat minat peserta didik terhadap kimia ditunjukkan pada pernyataan "ketika saya belajar, terkadang saya benar-benar terpikat terhadap kimia" baik untuk kelas eksperimen $(M=3,41 ; S D=0,68)$ maupun kelas kontrol $(M=3,03 ; S D=0,89)$ seperti yang ditunjukkan pada Tabel 2. Hal ini menunjukkan bahwa minat belajar kimia yang tinggi menumbuhkan kemauan belajar peserta didik yang tinggi pula. Tabel 2 menunjukkan peserta didik merasa tidak terlalu suka dengan kelas kimianya. Suasana yang menyenangkan di dalam kelas diperlukan agar pembelajaran menjadi lebih menarik dan nyaman. Bukan hanya peserta didik yang harus berperan dalam menciptakan suasana menyenangkan, namun peran guru juga sangat dibutuhkan. 


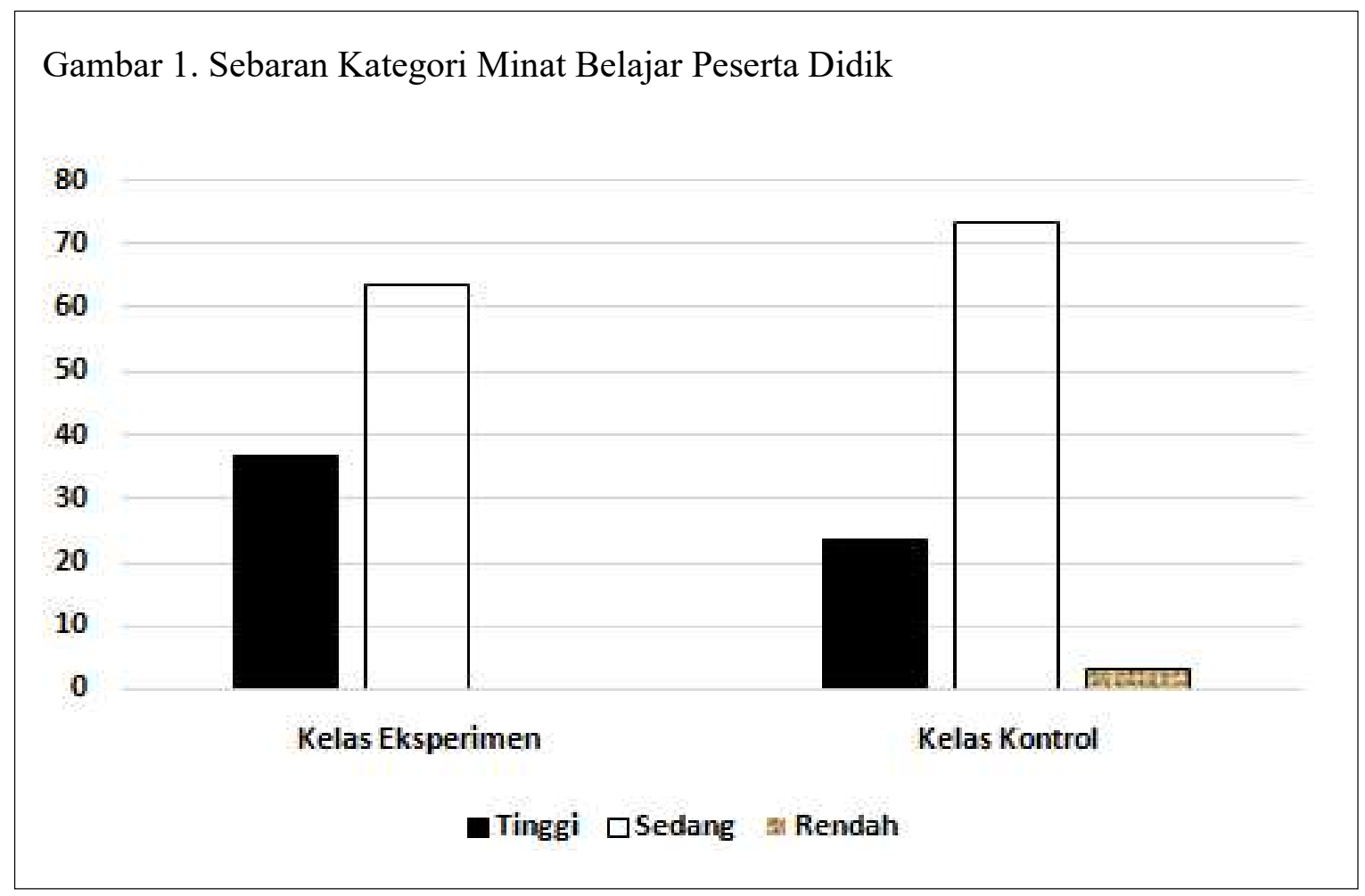

Tabel 2

Analisis Faktor Tingkat Minat Peserta Didik terhadap Kimia

\begin{tabular}{clcc}
\hline \multirow{2}{*}{ No } & \multicolumn{1}{c}{ Tingkat Minat dalam Kimia } & \multicolumn{2}{c}{ Mean } \\
\cline { 3 - 4 } & & Eksperimen (S.D) & Kontrol (S.D) \\
\hline \multirow{2}{*}{2} & Saya suka kelas kimia saya & $(0,63)$ & 2,33 \\
& Saya memiliki banyak pertanyaan tentang & 3,34 & $(0,84)$ \\
& topik kesetimbangan kimia dalam pikiran & $(0,77)$ & 2,33 \\
& saya. & & $(0,99)$ \\
3 & Semakin sering saya mempelajari kimia, & 3,00 & 2,23 \\
& semakin menarik untuk didalami. & $(0,76)$ & $(0,77)$ \\
4 & Kimia memiliki lingkup profesional yang & 2,86 & 2,83 \\
& sangat terbatas.* & $(0,69)$ & $(0,75)$ \\
5 & Saya merasa bosan ketika harus & 2,83 & 2,60 \\
& mempelajari kesetimbangan kimia.* & $(0,71)$ & $(0,86)$ \\
6 & Saya mengerjakan hal-hal yang & 3,03 & 2,80 \\
& tidak berkaitan dengan kimia selama & $(0,73)$ & $(1,03)$ \\
& pembelajaran kimia.* & & 3,03 \\
7 & Ketika saya belajar, terkadang saya benar- & 3,41 & $(0,89)$ \\
\cline { 2 - 4 } benar terpikat terhadap kimia. & $(0,68)$ & \\
\hline
\end{tabular}

Ket.: *Pernyataan negatif 
Pernyataan "saya memiliki banyak pertanyaan tentang topik kesetimbangan kimia dalam pikiran saya" juga disetujui oleh kelas eksperimen namun kurang disetujui oleh kelas kontrol. Hal ini menunjukkan bahwa peserta didik yang menerapkan model PBL memiliki rasa ingin tahu yang tinggi daripada kelas kontrol. Hal ini sejalan dengan Gunter dan Alpat (2016) yang menyatakan bahwa peserta didik lebih antusias dan lebih memiliki rasa ingin tahu dalam pembelajaran berbasis masalah, sedangkan peserta didik biasanya mendengarkan guru, mencatat definisi, dan rumus yang diberikan oleh guru dalam pembelajaran ekspositori. Sejalan juga dengan penjelasan Akram et al. (2017) bahwa rasa ingin tahu dapat membantu peserta didik untuk mengembangkan minat belajar kimia, demikian juga sebaliknya. Kurangnya rasa ingin tahu dapat menurunkan minat belajar kimia peserta didik.

Analisis faktor pilihan pribadi ditunjukkan oleh Tabel 3. Komponen minat mencakup komponen afektif dan kognitif. Komponen kognitif lebih erat kaitannya dengan perasaan pribadi tentang kimia (Herranen, Vesterinen, \& Aksela, 2015). Pilihan pribadi dan keputusan individu sangat penting dalam menentukan minat peserta didik terhadap kimia. Peserta didik mencapai keberhasilan yang relatif lebih tinggi dalam suatu mata pelajaran atau topik tertentu jika mereka tertarik daripada mereka yang kurang tertarik (Çiçek \& Ilhan, 2017). Respons tertinggi kedua adalah para peserta didik berusaha menjawab pertanyaan yang diajukan oleh guru. Guru harus menyadari bahwa minat belajar kimia peserta didik dapat ditingkatkan dengan adanya interaksi antara guru dengan peserta didik melalui diskusi dan tanya jawab.

Peran guru terlihat jelas berbeda antara kelas eksperimen dan kelas kontrol seperti ditunjukkan pada Tabel 4. Kelas kontrol memiliki respons lebih positif daripada kelas eksperimen. Tingkat persetujuan tertinggi ditunjukkan pada pernyataan "di kelas kimia, guru pandai menjelaskan hal-hal yang berkaitan dengan kimia" $(M=3,00, S D=0,74)$ dan "guru melakukan tanya jawab selama pembelajaran kimia" $(M=3,00, S D=0,69)$. Peran guru di kelas kontrol yang menerapkan model ekspositori lebih dominan daripada peran guru di kelas eksperimen yang menerapkan model PBL. Peserta didik tidak dituntut untuk menemukan materi secara mandiri, namun materi pelajaran disampaikan secara

Tabel 3

Analisis Faktor Pilihan Pribadi

\begin{tabular}{clcc}
\hline \multirow{2}{*}{ No } & \multicolumn{2}{c}{ Pilihan Pribadi } & \multicolumn{2}{c}{ Mean } \\
\cline { 3 - 4 } & & Eksperimen (S.D) & Kontrol (S.D) \\
\hline \multirow{2}{*}{1} & Kimia bermanfaat untuk memecahkan & 2,86 & 2,50 \\
& masalah sehari-hari. & $(0,79)$ & $(0,82)$ \\
2 & Saya berusaha menjawab pertanyaan yang & 3,24 & 2,83 \\
& diajukan guru. & $(0,44)$ & $(0,70)$ \\
3 & Saya hanya mempelajari pelajaran kimia & 2,79 & 2,60 \\
& jika ada ulangan.* & $(0,73)$ & $(1,10)$ \\
4 & Teori dalam kimia tidak dapat diubah atau & 3,31 & 2,93 \\
& dipertanyakan.* & $(0,54)$ & $(0,83)$ \\
\hline
\end{tabular}

Ket: *Pernyataan negatif 
Tabel 4

Analisis Faktor Peran Guru

\begin{tabular}{|c|c|c|c|}
\hline \multirow{2}{*}{ No } & \multirow{2}{*}{ Peran Guru } & \multicolumn{2}{|c|}{ Mean } \\
\hline & & Eksperimen (S.D) & Kontrol (S.D) \\
\hline 1 & $\begin{array}{l}\text { Guru kimia saya menggunakan bagan, } \\
\text { model, dan contoh kehidupan sehari- } \\
\text { hari untuk mengajarkan kami topik } \\
\text { kesetimbangan kimia. }\end{array}$ & $\begin{array}{c}2,59 \\
(0,78)\end{array}$ & $\begin{array}{l}2,70 \\
(0,88)\end{array}$ \\
\hline 2 & $\begin{array}{l}\text { Di kelas kimia, guru saya pandai menjelas- } \\
\text { kan hal-hal yang berkaitan dengan kimia. }\end{array}$ & $\begin{array}{c}2,55 \\
(0,63)\end{array}$ & $\begin{array}{c}3,00 \\
(0,74)\end{array}$ \\
\hline 3 & $\begin{array}{l}\text { Guru kimia saya memberikan banyak } \\
\text { perhatian kepada saya seperti halnya peserta } \\
\text { didik lain. }\end{array}$ & $\begin{array}{l}2,48 \\
(0,69)\end{array}$ & $\begin{array}{l}2,70 \\
(0,84)\end{array}$ \\
\hline 4 & $\begin{array}{l}\text { Guru saya juga menyediakan waktu ekstra } \\
\text { untuk membantu kami dalam mempelajari } \\
\text { kimia. }\end{array}$ & $\begin{array}{c}2,17 \\
(0,80)\end{array}$ & $\begin{array}{l}2,30 \\
(0,84)\end{array}$ \\
\hline 5 & $\begin{array}{l}\text { Guru melakukan tanya jawab selama } \\
\text { pembelajaran kimia. }\end{array}$ & $\begin{array}{c}2,86 \\
(0,64)\end{array}$ & $\begin{array}{c}3,00 \\
(0,69)\end{array}$ \\
\hline 6 & $\begin{array}{l}\text { Guru saya pasif selama pembelajaran } \\
\text { kimia.* }\end{array}$ & $\begin{array}{l}2,86 \\
(0,79)\end{array}$ & $\begin{array}{c}2,73 \\
(0,91)\end{array}$ \\
\hline
\end{tabular}

Ket: *Pernyataan negatif

langsung oleh guru karena pembelajaran ini menekankan pada proses penyampaian materi secara verbal dari seorang guru.

Peran guru sebagai fasilitator sangat penting karena berpengaruh kepada proses belajar peserta didik. Perkembangan sikap positif peserta didik tentang kimia sebagai mata pelajaran sekolah adalah salah satu tanggung jawab utama setiap guru kimia. Walaupun peserta didik lebih banyak belajar sendiri, guru memiliki peranan yang penting dalam pembelajaran. Tugas guru tidak hanya menyampaikan informasi kepada peserta didik, tetapi guru harus menjadi fasilitator yang bertugas memberikan kemudahan belajar kepada seluruh peserta didik agar mereka dapat belajar dalam suasana yang menyenangkan, penuh semangat, dan berani mengemukakan pendapat secara terbuka. Peran guru sebagai tutor adalah memantau aktivitas peserta didik, memfasilitasi proses belajar dan menstimulasi peserta didik dengan pertanyaan. Guru harus mengetahui dengan baik tahapan kerja peserta didik baik aktivitas fisik ataupun tahapan berpikir peserta didik. Cheung (2009) menjelaskan bahwa kualitas pembelajaran kimia adalah penentu penting dan pengaruh terkuat dari sikap peserta didik terhadap kimia.

Tabel 5 menjelaskan tentang minat situasional, yaitu berkaitan dengan kenikmatan atau keterlibatan peserta didik terhadap pembelajaran (Basso et al., 2018). Para peserta didik cenderung kurang tertarik dengan topik kesetimbangan kimia. Namun, mereka meyakini bahwa bidang kimia adalah disiplin ilmu yang penting dan penting untuk diketahui. Tingkat persetujuan tertinggi ditunjukkan pada pernyataan "saya pikir bidang kimia penting untuk saya ketahui" $(M=3,17 ; S D=0,60)$.

Peserta didik di kelas PBL merasa percaya diri untuk tampil di kelas karena 
Tabel 5

Analisis Faktor Minat Situasional

\begin{tabular}{|c|c|c|c|}
\hline \multirow{2}{*}{ No } & \multirow{2}{*}{ Minat Situasional } & \multicolumn{2}{|c|}{ Mean } \\
\hline & & Eksperimen (S.D) & Kontrol (S.D) \\
\hline \multirow[t]{2}{*}{1} & Saya terpesona dengan topik kesetimbangan & 2,38 & 2,27 \\
\hline & kimia. & $(0,68)$ & $(0,74)$ \\
\hline \multirow[t]{2}{*}{2} & Saya memilih untuk tampil karena & 2,34 & 2,00 \\
\hline & $\begin{array}{l}\text { saya benar-benar tertarik dengan topik } \\
\text { kesetimbangan kimia. }\end{array}$ & $(0,67)$ & $(0,74)$ \\
\hline \multirow[t]{2}{*}{3} & Saya sangat senang bisa mempelajari topik & 2,76 & 2,30 \\
\hline & kesetimbangan kimia. & $(0,74)$ & $(0,88)$ \\
\hline \multirow[t]{2}{*}{4} & Saya sangat menantikan untuk belajar lebih & 2,97 & 2,03 \\
\hline & banyak tentang kimia. & $(0,63)$ & $(0,72)$ \\
\hline \multirow[t]{2}{*}{5} & Saya pikir bidang kimia adalah disiplin ilmu & 2,93 & 2,80 \\
\hline & yang penting. & $(0,70)$ & $(0,71)$ \\
\hline \multirow[t]{2}{*}{6} & Saya pikir bidang kimia penting untuk saya & 3,17 & 2,60 \\
\hline & ketahui. & $(0,60)$ & $(0,72)$ \\
\hline \multirow[t]{3}{*}{7} & Saya merasa minder untuk tampil di & 3,00 & 2,57 \\
\hline & kelas karena saya tidak suka dengan topik & $(0,65)$ & $(0,90)$ \\
\hline & kesetimbangan kimia.* & & \\
\hline
\end{tabular}

Ket: *Pernyataan negatif

mereka menyukai topik kesetimbangan kimia. Hal ini menjadi aspek yang sangat penting untuk ditingkatkan agar peserta didik menjadi lebih percaya diri dan tertarik terhadap materi yang dipelajari, khususnya kesetimbangan kimia. Peserta didik merasa yakin dengan hasil diskusi kelompok untuk menampilkan atau mempresentasikan hasil karya mereka di kelas. Selanjutnya, guru membantu peserta didik untuk menganalisis dan menyimpulkan materi yang baru saja dipelajari. Guru juga perlu memberikan waktu yang efektif dan efisien selama pembelajaran karena peserta didik menantikan untuk belajar lebih banyak tentang kimia.

Analisis faktor kemauan mengikuti pembelajaran kimia menunjukkan bahwa peserta didik memiliki sikap positif terhadap kimia. Respons positif peserta didik ditunjukkan pada pernyataan "saya tidak pernah mencatat yang dijelaskan oleh guru selama mengikuti pembelajaran kimia" baik pada kelas eksperimen $(M=3,55$; $S D=0,57)$ maupun pada kelas kontrol $(M=2,90 ; S D=0,84)$. Peserta didik kurang setuju dengan pernyataan tersebut seperti yang ditunjukkan pada Tabel 6. Hal ini menunjukkan bahwa peserta didik akan mencatat materi yang disampaikan oleh guru.

Respons positif selanjutnya untuk kelas eksperimen adalah "saya malas mengikuti diskusi kelompok yang dilakukan selama pembelajaran topik kesetimbangan kimia" $(M=3,17 ; S D=0,71)$. Kelas PBL dituntut untuk dapat melakukan diskusi kelompok sehingga mereka dapat menemukan konsep dari topik kesetimbangan melalui kegiatan kolaborasi.Aspek ini menjadi sangat penting karena setiap peserta didik akan terlibat dan memiliki peran dalam proses pembelajaran sehingga pembelajaran menjadi lebih bermakna. Respons positif selanjutnya 
Tabel 6

Analisis Faktor Kemauan Mengikuti Pembelajaran Kimia

\begin{tabular}{|c|c|c|c|}
\hline \multirow{2}{*}{ No } & \multirow{2}{*}{ Kemauan Mengikuti Pembelajaran Kimia } & \multicolumn{2}{|c|}{ Mean } \\
\hline & & Eksperimen (S.D) & Kontrol (S.D) \\
\hline 1 & $\begin{array}{l}\text { Saya berusaha untuk hadir tepat waktu pada } \\
\text { jam pembelajaran topik kesetimbangan } \\
\text { kimia. }\end{array}$ & $\begin{array}{c}3,07 \\
(0,65)\end{array}$ & $\begin{array}{c}2,67 \\
(0,84)\end{array}$ \\
\hline 2 & $\begin{array}{l}\text { Saya berusaha untuk tidak meninggalkan } \\
\text { kelas ketika pembelajaran topik } \\
\text { kesetimbangan kimia berlangsung. }\end{array}$ & $\begin{array}{c}3,03 \\
(0,82)\end{array}$ & $\begin{array}{c}2,77 \\
(0,86)\end{array}$ \\
\hline 3 & $\begin{array}{l}\text { Saya malas mengikuti diskusi kelompok } \\
\text { yang dilakukan selama pembelajaran topik } \\
\text { kesetimbangan kimia.* }\end{array}$ & $\begin{array}{c}3,17 \\
(0,71)\end{array}$ & $\begin{array}{l}2,63 \\
(0,81)\end{array}$ \\
\hline 4 & $\begin{array}{l}\text { Saya senang berdiskusi dengan teman } \\
\text { tentang topik kesetimbangan kimia. }\end{array}$ & $\begin{array}{l}2,86 \\
(0,64)\end{array}$ & $\begin{array}{c}2,53 \\
(0,78)\end{array}$ \\
\hline 5 & $\begin{array}{l}\text { Saya lebih suka mengobrol dengan teman } \\
\text { daripada mendengarkan penjelasan tentang } \\
\text { topik kesetimbangan kimia.* }\end{array}$ & $\begin{array}{c}2,97 \\
(0,91)\end{array}$ & $\begin{array}{l}2,70 \\
(0,95)\end{array}$ \\
\hline 6 & $\begin{array}{l}\text { Saya tidak pernah mencatat yang dijelaskan } \\
\text { oleh guru selama mengikuti pembelajaran } \\
\text { kimia.* }\end{array}$ & $\begin{array}{c}3,55 \\
(0,57)\end{array}$ & $\begin{array}{c}2,90 \\
(0,84)\end{array}$ \\
\hline
\end{tabular}

Ket: *Pernyataan negatif

untuk kelas kontrol adalah "saya berusaha untuk tidak meninggalkan kelas ketika pembelajaran topik kesetimbangan kimia berlangsung" $(M=2,77 ; S D=0,86)$. Peserta didik memiliki kemauan untuk mengikuti pembelajaran kimia dan berusaha untuk tetap berada di dalam kelas.

Jenis kelamin juga merupakan faktor yang berperan dalam minat belajar peserta didik (Krapp \& Prenzel, 2011). Penelitian ini menunjukkan bahwa peserta didik laki-laki $(72,50)$ lebih tertarik pada kimia daripada peserta didik perempuan $(72,17)$ di kelas eksperimen. Kelas kontrol menunjukkan bahwa peserta didik perempuan $(66,58)$ lebih tertarik pada kimia daripada peserta didik laki-laki (63,52). Secara keseluruhan, hasil yang diperoleh adalah peserta didik laki-laki $(69,13)$ lebih tertarik pada kimia daripada peserta didik perempuan $(68,98)$. Krapp dan Prenzel (2011) menyatakan bahwa kimia adalah bidang subjek yang kurang diminati oleh anak perempuan dibandingkan anak laki-laki. Sejumlah penelitian sebelumnya menunjukkan bahwa peserta didik laki-laki lebih tertarik pada kimia daripada peserta didik perempuan (Baram-Tsabari \& Yarden, 2005). Sebaran kategori minat belajar peserta didik berdasarkan jenis kelamin ditunjukkan pada Gambar 2.

Minat peserta didik terhadap kimia masih rendah. Kimia dianggap sebagian besar peserta didik menjadi mata pelajaran yang sulit untuk dipahami. Salta dan Tzougraki (2004) menjelaskan bahwa selain kesulitan yang dimiliki peserta didik dalam memahami dan menerapkan konsep kimia, mereka juga mengalami kesulitan dalam memecahkan masalah kimia. Berbagai upaya harus dilakukan oleh guru agar suasana pembelajaran menjadi lebih menarik, inovatif, dan berorientasi 


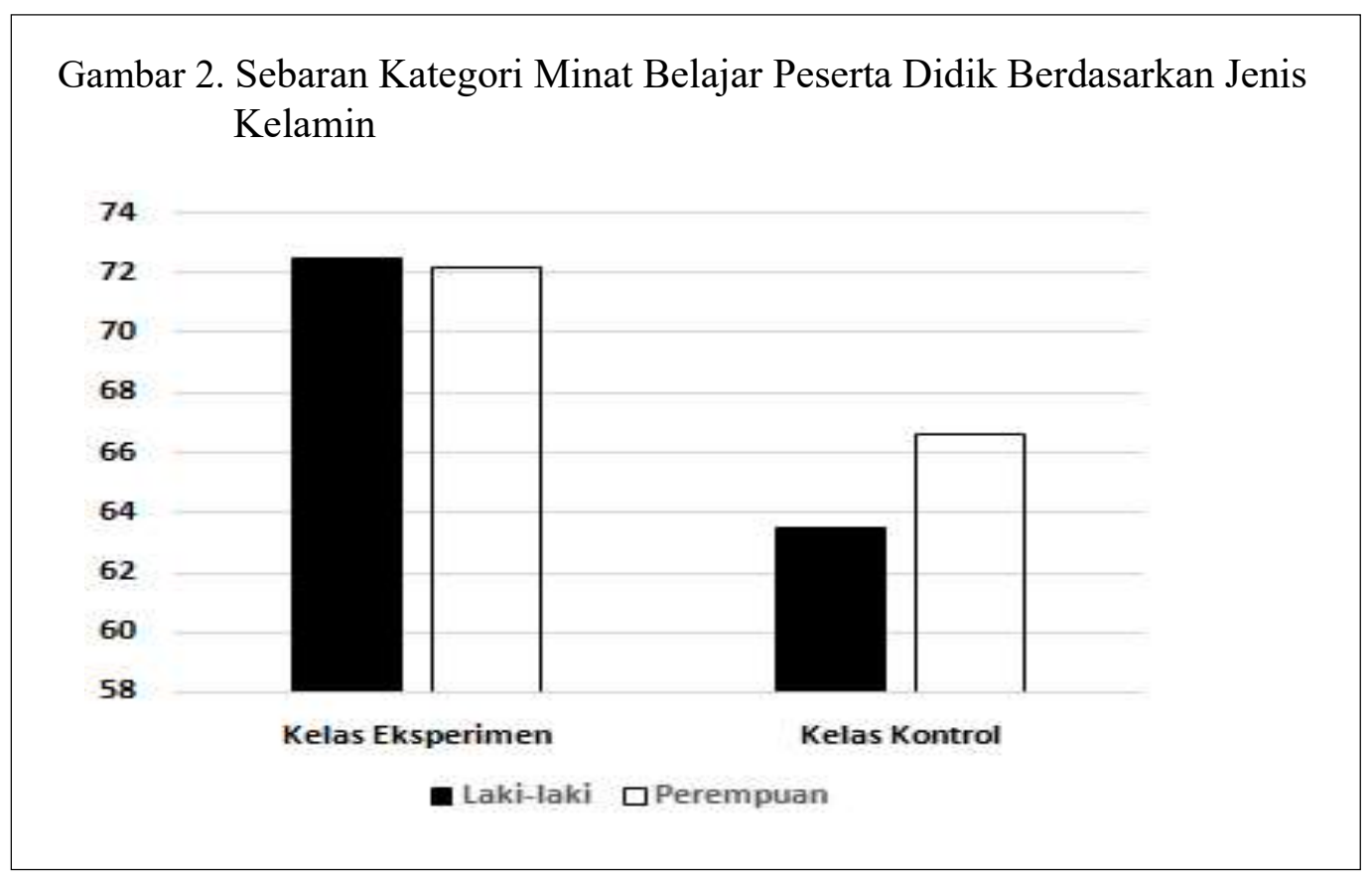

pada peserta didik. Cara potensial untuk meningkatkan minat peserta didik pada kimia adalah dengan menggunakan konteks sosial dan kehidupan nyata sebagai titik awal pengembangan ide-ide ilmiah (Bennet, Lubben, \& Hogarth, 2007). Penggunaan skenario yang diterapkan dalam model PBL dimaksudkan untuk meningkatkan minat peserta didik dalam kimia.

\section{SIMPULAN}

Terdapat perbedaan signifikansi minat belajar antara peserta didik yang menerapkan model pembelajaran PBL dan model pembelajaran ekspositori pada materi kesetimbangan kimia. Minat peserta didik dominan pada 'kategori cukup baik di kelas eksperimen maupun di kelas kontrol. Minat peserta didik dalam kimia tidak tinggi. Peran guru merupakan faktor penting dalam mengembangkan minat peserta didik. Guru kimia sebagai fasilitator diharapkan mampu mengembangkan minat peserta didik melalui proses belajar mengajar yang berorientasi pada peserta didik dan menghubungkan materi dengan kehidupan nyata. Peserta didik juga perlu mengembangkan minat belajar kimia dengan meningkatkan rasa ingin tahu, menciptakan suasana kelas, dan memiliki kemauan yang tinggi untuk mengikuti pembelajaran kimia.

\section{DAFTAR PUSTAKA}

Adodo, S. O., \& Gbore, L. O. (2012). Prediction of attitude and interest of science students of different ability on their academic performance in basic science. International Journal of Psychology and Counselling, 4(6), 68-72. https://doi.org/10.5897/ ijpc10.049.

Akram, M., Surif, J. Bin, \& Ali, M. (2014). Conceptual difficulties of secondary school students in electrochemistry. Asian Social Science, 10(19), 276281. https://doi.org/10.5539/ass. v10n19p276.

Akram, T. M., Ijaz, A., \& Ikram, H. (2017). Exploring the factors responsible for declining students' interest in chemistry. International Journal 
of Information and Education Technology, 7(2), 88-94. https://doi. org/10.18178/ijiet.2017.7.2.847.

Baram-Tsabari, A., \& Yarden, A. (2005). Characterizing children's spontaneous interests in science and technology. International Journal of Science Education, 27(7), 803-826. https:// doi.org/10.1080/09500690500038389

Bennet, J., Lubben, F., \& Hogarth, S. (2007). Bringing science to life: A synthesis of the research evidence on the effects of context-based and STS approaches to science teaching. Science Education, 91(3), 347370. doi:10.1002/sce.20186.

Basso, A., Chiorri, C., Bracco, F., Carnasciali, M. M., Alloisio, M., \& Grotti, M. (2018). Improving the interest of high-school students toward chemistry by crime scene investigation. Chemistry Education Research and Practice, 19(2), 558-566. https://doi. org/10.1039/c7rp00232g.

Cheung, D. (2009). Students' attitudes toward chemistry lessons: The interaction effect between grade level and gender. Research in Science Education, 39(1), 75-91. https://doi. org/10.1007/s11165-007-9075-4.

Çiçek, Ö., \& Ilhan, N. (2017). Evaluating interest in acids-bases: Development of an acid-base interest scale (ABIS) and assessment of pre-service science teachers' interest. Chemistry Education Research and Practice, 18(4), 630-640. https://doi.org/10.1039/c6rp00238b.

Golightly, A., \& Raath, S. (2015). Problembased learning to foster deep learning in preservice geography teacher education. Journal of Geography, 114(2), 58-68. https://doi.org/10.1080 /00221341.2014.894110.

Gunter, T., \& Alpat, S. K. (2016). The effects of problem-based learning
(PBL) on the academic achievement of students studying 'electrochemistry'. Chemistry Education Research and Practice, 18(1), 78-98. https://doi. org/10.1039/C6RP00176A.

Herranen, J. K., Vesterinen, V. M., \& Aksela, M. K. (2015). How to measure elementary teachers' interest in teaching chemistry? Chemistry Education Research and Practice, 16(2), 408-416. https://doi.org/10.1039/c4rp00246f.

Hofstein, A., \& Mamlok-Naaman, R. (2011). High-school students' attitudes toward and interest in learning chemistry. Educacion Quimica, 22(2), 90-102. https://doi.org/10.1016/s0187893x(18)30121-6.

Hosnan, M. (2014). Pendekatan saintifik dan kontekstual dalam pembelajaran abad 21. Bogor: Ghalia Indonesia.

Komariah, K., Sofyan, H., \& Wagiran. (2019). Problem-based learning: Implementasi dan urgensinya bagi peningkatan kualitas pembelajaran. Jurnal Kependidikan, 3(2), 207-219. Diunduh dari https://journal.uny.ac.id/ index.php/jk/article/view/20792/pdf.

Krapp, A., \& Prenzel, M. (2011). Research on interest in science: Theories, methods, and findings. International Journal of Science Education, 33(1), 27-50. https://doi.org/10.1080/09500 693.2010.518645.

Maharani, I., Rahayu, S., \& Fajaroh, F. (2019). Pengaruh pembelajaran inkuiri berkonteks socioscientific-issues terhadap keterampilan berpikir kritis dan scientific explanation. Jurnal Kependidikan, 3(1), 53-68. Diunduh dari https://journal.uny.ac.id/index. php/jk/article/view/20972/pdf.

Overton, T. L., \& Randles, C. A. (2015). Beyond problem-based learning: Using dynamic PBL in chemistry. Chemistry Education Research and 
Practice, 16(2), 251-259. https://doi. org/10.1039/c4rp00248b.

Salta, K., \& Tzougraki, C. (2004). Attitudes toward chemistry among 11 th grade students in high schools in Greece. Science Education, 88(4), 535-547. https://doi.org/10.1002/sce.10134.

Suyanta, Laksono, E. W., Fadhilah, N. F., \& Rizky, I. (2019). The effect of problembased learning on students' self-regulated learning of chemistry learning. Jurnal Kependidikan, 3(2), 187-193. Diunduh dari https://journal.uny.ac.id/index.php/ jk/article/view/19695/pdf.
Taber, K. S. (2011). Constructivism as educational theory: Contingency in learning and optimally guided instruction. Dalam Jaleh Hassakhah (Ed.), Educational theory (pp. 39-61). Hauppauge, N. Y.: Novapublishers.

Tarhan, L., Ayar-Kayali, H., Urek, R. O., \& Acar, B. (2008). Problem-based learning in $9^{\text {th }}$ grade chemistry class: Intermolecular forces. Research in Science Education, 38(3), 285-300. https://doi.org/10.1007/s11165-0079050-0. 